of prospective medical students. Psychiatric Bulletin, 27, $30-32$.

O'Dwyer, J. M. (1999) Psychiatric training of pre-registration house officers. Psychiatric Bulletin, 23, 283-285.

O'Neale, J. (2002) Stealing doctors. Triple Helix, Autumn, $14-16$.

Paice, E. (2001) Women in hospital medicine. Clinical medicine. Journal of the Royal College of Physicians of London, 1, 344-345.

Royal College of Psychiatrists (2002) Annual Census of Psychiatric Staffing 2001 (Occasional Paper OP54). London: Royal College of Psychiatrists.

- (2003) Model Consultant Job Descriptions and Recommended Norms (Occasional Paper OP55). London: Royal College of Psychiatrists.

Sainsbury Centre for Mental Health (2000) Finding and Keeping: Review of Recruitment and Retention in the Mental Health Workforce. London: Sainsbury Centre for Mental Health.

Terkel, S. (1972) Working: People Talk About What They Do All Day And About How They Feel About What They Do. New York: The New Press.

Weintraub, W., Plaut, S. \& Weintraub, E. (1999) Recruitment into psychiatry: increasing the pool of applicants. Canadian Journal of Psychiatry, 44, 473-477.

\section{Multiple choice questions}

1 Recruiting and retaining an effective psychiatric workforce:

a is only a problem for doctors

$\mathrm{b}$ is a major issue in most developed and developing countries

c would be helped in the short-term by increasing $\mathrm{SHO}$ numbers

d requires attention to possible solutions at every stage of the career pathway

e should be helped by encouraging new styles of working for existing consultants.

2 For aspiring medical students:

a the only acceptable route into medicine is via good science A-levels or equivalent

b new fast-track graduate entry programmes are proving popular c the number of medical school places in the UK will double between 2002 and 2005

d more males than females are applying for places

e targeting mature entrants to courses with information about mental health careers may encourage recruitment into psychiatry later.

3 For doctors in the SHO grade in psychiatry:

a only a minority expect to become consultant psychiatrists

b a major attraction to a psychiatric career is the multidisciplinary working

c working in a safe environment is a key issue for retention on the career pathway

d they would have had little competition to obtain their posts

e using psychiatric SHO posts for general practice trainees should help to improve the quality of mental health care overall.

4 For consultant psychiatrists:

a the majority continue working until the normal retirement age of 65

b most are happy with their current workloads

c increased bureaucracy is a commonly cited reason for wanting to retire early

$\mathrm{d}$ few intend to do any mental health work after retirement

e flexible patterns of working throughout consultant careers would help to retain experienced staff longer.

\section{MCQ answers}

$\begin{array}{lllll}\text { 1 } & & \text { 2 } & 3 & 4 \\ \text { a F } & \text { a F } & \text { a F } & \text { a F } \\ \text { b T } & \text { b T } & \text { b T } & \text { b F } \\ \text { c F } & \text { c F } & \text { c T } & \text { c T } \\ \text { d T } & \text { d F } & \text { d F } & \text { d F } \\ \text { e T } & \text { e T } & \text { e T } & \text { e T }\end{array}$

\title{
INVITED COMMENTARY ON Recruiting and retaining psychiatrists
}

Sally Pidd's article (2003, this issue) gives a structured analysis of the key issues and some potential solutions to recruitment and retention problems in psychiatry. My perspective on this is influenced by personal experiences. These include my own career, my involvement with the Collegiate Trainees' Committee, and hearing the views of students, peers and consultants.

\section{Why do people enter psychiatry?}

One of the attractions of psychiatry is that it encompasses a wide range of perspectives and treatment approaches. A broad range of experience in staff is also valued. My experiences of working in accident and emergency and in New Zealand were viewed positively at my specialist registrar (SpR) interview. 
Pidd discusses other reasons given for taking up careers in psychiatry. However, research or direct questioning will not always reveal motivations underlying career choice. For example, people may overemphasise altruism and be reluctant to discuss factors they consider less socially desirable. Furthermore, individuals entering helping professions as a sublimation of their own needs, whether constructive or destructive, are unlikely to be obvious to an interview panel or to themselves.

\section{Why do they stay?}

Psychiatry is an enjoyable, varied and challenging profession. The demands of the job can be stressful. In the right context this can be a source of job satisfaction. My first post in psychiatry immediately followed work in obstetrics. I felt more tired after a night consisting of three psychiatric assessments and sleep than one spent entirely awake on a labour ward. However, genuine attention was paid to my supervision needs, professional development and general well-being, not just to my place as a service provider. The importance of good supervision is a recurrent theme raised by trainees in surveys, informal discussions and College approval visits. Multi-disciplinary team working can also be a source of expertise, mutual support and sharing of responsibility.

\section{Why do they leave?}

Medical students and doctors are not immune to cultural and social influences. Public perceptions of mental illness and psychiatrists are often negative and inaccurate. Psychiatrists in television and film are frequently portrayed as bemused eccentrics at best and emotionally damaged at worst. In the factual media there is an emphasis on violence perpetrated by people with mental disorders and the role of psychiatrists as protectors of the public. This serves to dissuade people from careers in psychiatry and disillusion those already embarked on them.

Loss of potential consultants into non-consultant career grade posts may reflect insufficient flexibility in the traditional career pathway. Some wish to gain more experience before career progression, others find external commitments incompatible with training posts. Initiatives to improve work-life balance may not be enough to cope with work-babyexam balance. The examination itself can also directly lead to senior houses officers leaving training posts. This relates to the pressures of studying on top of a full-time job and the perception that the examination is still not a valid measure of the skills and qualities necessary to be a psychiatrist.

Job satisfaction in consultants is essential not only to maintain them in their posts but also to encourage others to remain in psychiatry. There seems to be a growing sense of disillusionment within general adult psychiatry in particular. The rapid expansion of well-resourced sub-speciality posts may leave community mental health teams depleted of staff and of some of the enjoyable and satisfying parts of their work. Another major source of frustration is the perception of accountability without control. A significant number of SpRs are choosing to take locum consultant posts when they gain their Certificate of Completion of Specialist Training. This can offer them greater control over working patterns, less perceived accountability and the opportunity to try out a job with the option of leaving. I consider these factors more influential than the financial incentives of locum posts. If $\mathrm{SpRs}$ view a substantive post as being excessively stressful, unsupported and the workload unmanageable, they obviously will not take it.

Finally, it is important to recognise that leaving may not always be the wrong choice. The job may be wrong for the person or the person may be wrong for the job.

\section{What could improve recruitment and retention?}

\section{Flexibility of career structure}

A profession that values a broad range of experience and encourages students, trainees and consultants in pursuing this will be attractive to enter and to remain in.

\section{Doctors' well-being}

Supervision, mentoring and adequate training have been highlighted by Pidd and others as positive strategies to assist trainees and consultants. The requirement for support, reflection on practice and assistance with professional development cannot be wholly met by the record in training assessment and appraisal processes. Their assessment function inevitably leads to less openness than is possible within the settings of supervision, mentoring and continuing professional development peer groups.

At an organisational level, reduction in hours is only one aspect of improving conditions for doctors. The European Working Time Directive may lead to a reduction in consultant hours but compound existing workforce problems. Attention must be paid to the development of manageable workloads and 
working patterns for consultants. As Sally Pidd observes, it is necessary for job plans to be accurate and to reflect jobs that are 'attractive and do-able'.

\section{Positive models of psychiatry}

Students and house officers often have narrow, negative, ward-based experiences of psychiatry. 'Why does this woman keep taking overdoses? Why don't the psychiatrists do something?' are questions I asked and now overhear. General practice trainees can end up in the unpopular posts on training schemes that the psychiatry trainees know to avoid. Good student attachments, links with liaison psychiatry and attention to trainees' evaluation of posts can improve this. Unfinished Business (Department of Health, 2002) contains the proposal that all doctors be exposed to training in psychiatry as part of basic training.

Anti-stigma campaigns and proactive psychiatrists working with the media on fact and fiction may chip away at some of the negative stereotypes.

As discussed by Pidd, better conditions for patients and staff on in-patient units are essential.

\section{Increased numbers of doctors}

The planned expansion of numbers of medical students is helpful. Further restructuring of how doctors are provided in this country, with the removal of limitations on numbers entering training, could potentially solve workforce problems. Excessive recruitment at early stages would fill posts. For example, the number of law graduates greatly exceeds the number of training and substantive posts available. However, this wastes resources and is detrimental to individuals.

\section{What could make it worse?}

\section{Exit examinations}

Competency is an evolving process, not an end point. Subjecting experienced professionals to another round of examinations will disenchant and discourage them.

\section{Mental Health Act reform}

If the proposals for the England and Wales Mental Health Bill are adopted in law, the role of a psychiatrist may change to the degree that people leave the profession or no longer wish to join it. In Scotland the new Mental Health (Care and Treatment) (Scotland) Act 2003 has considerable workforce implications.

\section{Loss of career flexibility}

Proposals for reform of the senior house officer grade (Department of Health, 2002) include timelimited training. Pressure to fill vacant posts is also leading to less flexibility in higher specialist training. Increasingly rigid models of training aimed at producing doctors quickly for service provision are likely to be counterproductive. SpRs will be reluctant to take substantive posts that they feel personally or professionally unprepared for. Countering this by developing a new generalist sub-consultant grade would further demoralise the profession and undermine appropriate training.

\section{Conclusion}

Care must be taken to ensure that the strategies proposed to improve recruitment and retention in psychiatry do not become part of the problem. There must be a balance between the needs of the individual and of the organisation. The importance of getting the right people in the right posts must not be forgotten.

\section{References}

Department of Health (2002) Unfinished Business: Proposals for Reform of the Senior House Officer Grade. London: Department of Health.

Pidd, S. (2003) Recruiting and retaining psychiatrists. Advances in Psychiatric Treatment, 9, 405-411.

Judith Halford Specialist Registrar Liaison Psychiatry, Ravenscraig Hospital, Inverkip Road, Greenock PA16 9HA, UK 